\title{
Erken Tip ilaç Alerijsi Sıklığının ve Test Sonuçlarının Değerlendirilmesi: Sakarya Bölgesinden Retrospektif bir Çalışma
}

\section{Evaluation of Prevalence of Early Type Drug Allergy and Test \\ Results: A Retrospective Study from Sakarya Region}

\author{
Kadriye Terzioğlu', Özgür Sancar², Hasan Çetin Ekerbiçer², \\ Raziye Tülümen Öztürk ${ }^{3}$
}

' Sakarya Üniversitesi Tıp Fakültesi Eğitim ve Araştırma Hastanesi, Göğüs Hastalıkları, Erişkin Alerii ve İmmünoloji Birimi, Sakarya

${ }^{2}$ Sakarya Üniversitesi Tıp Fakültesi Eğitim ve Araşııma Hastanesi, Halk Sağlığı A.D, Sakarya

${ }^{3}$ Bursa Devlet Hastanesi, Erişkin Alerii ve Immünoloji Birimi, Bursa

Yazışma Adresi / Correspondence:

Kadriye Terzioğlu

Sakarya Üniversitesi Tıp Fakültesi Eğitim ve Araştırma Hastanesi, Göğüs Hastalıkları, Erişkin Alerji ve İmmünoloji Birimi, Sakarya

T: + $905336525359 \quad$ E-mail: dr.kadriyete@gmail.com

Geliş Tarihi / Received : 27.11.2018 Kabul Tarihi / Accepted : 11.12.2018

Öz

Amaç ilaçlarla ortaya çıkan aşııı duyarllık reaksiyonlarının gerçek sıklığına ait veriler sınırlııır. Dünyada ve ülkemizin çeşitli bölgelerinden ilaç alerii sıklğı̆nı ve ilaç alerii dağılımını bildiren cesittli yayınlar yapılmısțr. Bu çalșmada Sakarya bölgesindeki bir erișkin aleriji ve immunoloji polikliniggine ilaç alerjisi nedeni ile başvuran hastaların ilaç alerjisi dağı̆ımının, ilaç alerji test sonuçlarının ve alternatif olarak güvenle kullanabildikleri ilaçların dağıımının araştııııması amaçlandı. . ( Sakarya Tip Dergisi 2018, 8(4):759-765 )

Gereç ve Sakarya Üniversitesi Eğitim ve Araştırma Hastanesi Erişkin Alerji ve İmmunoloji Polikliniğine 2016-2018 yılları arasında ilaç alerji şikâyeti ile Yöntemler başvuran 213 hastanın dosyaları geriye dönük olarak incelendi. Tanımlayıcı tipte olan çalıșmaya tip 1 ilaç alerjisi olan 108 hasta dahil edildi. Hastaların yaş, cinsiyet, reaksiyona neden olan şüpheli ilaç(lar), deri testi ve oral provokasyon testi sonuçları, plasebo ile semptom oranları, alternatif olarak güvenle kullanabildikleri ilaç verileri incelendi.

Bulgular ilaç alerjisi ile başvuran 213 hastanın 105 'inde cox-1 aracılı nonsteroid antienflamatuar ilaç (NSAii) alerjisi mevcuttu. Geri kalan erken tip 1 ilaç alerjisi olan 108 hastanın verileri incelendi. Kadın/erkek oranı $96(\% 88,9) / 12(\% 11,1)$, yaş ortalaması 44,1 $\pm 12,1$ standart sapma idi. Öyküye dayalı ilac alerji dağııımı penisilin $\% 55$, sefalosporin $\% 46,7$, analjezikler $\% 38$ oranlarında bulundu. 38 hastaya 53 șüpheli ilaç ile, 80 hastaya 105 alternatif ilaç ile test yapıldı. Şüpheli ilaç ile yapılan testlerde $17(\% 44,7)$ hastada pozitiflik saptandı. Alternatif amaçla yapılan testlerde $\% 11,4$ oranında pozitiflik saptandı.

Sonuç illaç alerjisi nedeni ile başvuran hastaların tanısal testler ile değerlendirilmesi sonucunda gerçekte büyük bir kısmında ilaç alerjisi olmadığı saptanmaktadır. Bu sebeple ilaç alerjisinde öyküye dayalı ilaçların direkt yasaklanmasının doğru olmadığı ve alternatif ilaç seçiminde muhakkak öncesinde testlerin yapılması gerektiği sonucuna varılabilir.

Anahtar $\quad$ illaç alerjisi; hipersensitivite; tip 1 ilaç reaksiyonu; ilaç provokasyon testi; anafilaksi

Kelimeler

\section{Abstract}

Objective Data on real life frequency of drug induced hypersensitivity reactions are scarce. There are several publications from different countries around the word and also from our country regarding the frequency of drug induced allergy and distribution of related drugs. The aim of this study was to investigate the distribution of drug allergy, drug allergy test results, and the distribution of drugs that they could safely use in patients admitted to an adult allergy and immunology clinic in Sakarya region due to drug allergy. (Sakarya Med J 2018, 8(4):759-765 ).

Materials and The files of 213 patients who were admitted to Allergy and Immunology Outpatient Clinic at Sakarya University Training and Research Hos-

Methods pital with initial diagnosis of drug allergy between 2016-2018 were retrospectively analyzed. Research is a descriptive study. 108 patients were included in the study. Age, sex, suspected drug(s) causing the reaction, skin test and oral provocation test results, symptom rates with placebo, and alternative safe drugs for patients were examined.

Results Of the 213 patients presenting with suspected drug allergy, 105 had an allergy to COX-1 mediated non-steroidal anti-inflammatory drugs (NSAIDs). The data of 108 patients with early type 1 drug allergy were examined. 96 of the patients were female $(88,9 \%)$, and the mean age was $44 \pm 12$. $55 \%$ of the patients had a history of an allergy with penicillin, $46,7 \%$ with cephalosporin and $38 \%$ with analgesics. 38 patients were tested with 53 suspected drugs and 80 patients were tested with 105 alternative drugs. In drug provocation test, 17 (44,7\%) patients had positive test with suspected drug, and $11,4 \%$ of patients had positive test with alternative drugs.

Conclusion Most of the patients who were evaluated for drug allergy eventually does not have a true drug allergy. Thus, suspected drugs should not be restricted permanently based solely on anamnesis and drug provocation tests should be performed prior to permanent prohibition of a drug and also for an alternative drug selection.

Keywords Drug allergy; hypersensitivity; type 1 drug reaction; drug provocation test; anaphylaxis 


\section{Giriş}

Illaç alerjisi immunolojik mekanizma ile ortaya çıkan ilaç hipersensitivite reaksiyonu olarak tanımlanmaktadır. Tıbbın ilerlemesi, yeni keşfedilen birçok ilacın tıpta kullanıma girmesi ve artan ilaç kullanımı ile ilaç reaksiyonlarının daha fazla gözlenmesi hekimler için ciddi problemler oluşturmaya başlamıştır.

ilaç hipersensitivite reaksiyonları erken ve geç tip olarak sınıflandırılmaktadır. Erken tip ilaç alerjisi ilk 1-6 saat içinde gözlenmekte, IgE araclı Tip 1 reaksiyondur ve en sık ürtiker anjioödem olarak karşımıza çıkmaktadır. İlaca bağlı anafilaksi de bu grupta değerlendirilmektedir. Geç tip ilaç alerjisi ise ilk 24 saatten sonra gözlenen reaksiyonlar olup, Tip 4 reaksiyon şeklinde ortaya çıkar. illaç erüpsiyonları, toksik epidermal nekrolizis ve Stevens Johnson Sendromu bu gruba örnek verilebilir. ${ }^{1-3}$ En sık ilaç alerjisine neden olan ilaçlar arasında beta-laktam grubu antibiyotikler ve analjezikler bulunmaktadır. Yaygın kullanılan bu ilaçların alerjik reaksiyonları hafif klinik tablodan, ölümcül klinik tablolara kadar değişkenlik gösterebilmektedir. ${ }^{4}$

Illaçlarla ortaya çıkan aşırı duyarlıık reaksiyonlarının gerçek sıkığına ait veriler sınırlıdır. ${ }^{5}$ Bunun bir çok sebebi vardır; araştırmaların belli bir seçilmiş grubu ve özel reaksiyonları kapsaması, tanının sıklıkla hasta öyküsüne dayanması, tanısal testlerin kullanılmaması, enfeksiyon nedenli döküntülerin ve ilaç yan etkilerinin ilaç alerjisi olarak bildirilmesi sayılabilir. ${ }^{6}$ Yapılan araştırmalarda hastanede yatan hastaların \%15,1'inde istenmeyen ilaç reaksiyonlarının geliştiği ve bunların \%6,7 'sinin ciddi reaksiyonlar olduğu bildirilmiştir.?

Illaç alerjilerinde hekimler için en büyük sorunlardan biri, ilaç alerjisi ile başvuran hastaların anamnezinde aynı anda birden çok ilaç kullanım öyküsü olması nedeniyle sorumlu ilacı saptamada ki zorluktur. Hastadan alınan ayrıntılı anamnez, tanısal amaçlı yapılan deri prick testi, intradermal test (iDT) ve oral provokasyon testleri (OPT) ile sorumlu ilaç saptanabilmektedir. ${ }^{8}$ ilaç alerjisi ile başvuran hastalarda alerjiye sebep olan ilacın saptanması ve sorumlu olan ilacın yasaklanarak kullanabileceği alternatif ilacın tespit edilmesi, hastanın sonrasında alacağı tedavilerin düzenlenmesinde kendisi ve hekimler için oldukça önemlidir. ${ }^{9}$

Dünyada ve ülkemizde ilaç alerjisine dair çeşitli araştırmalar yapılmaktadır. Bu doğrultuda ilaç alerji rehberleri güncellenmekte ve hastaya yaklaşım konusunda daha veriye ulaşılmaktadır. Bu amaçla European Network for Drug Allergy (ENDA) kılavuzu en sık başvurulan kaynaklardan biridir. ${ }^{10}$

Bu çalışmada Sakarya bölgesinde ilaç alerjisi nedeni ile erişkin alerji ve immunoloji polikliniğine başvuran hastaların ilaç alerji dağı̆ımının, ilaç alerji test sonuçlarının ve alternatif olarak güvenle kullanabildikleri ilaçların dağııııının araştırılması amaçlandı.

\section{Gereç ve Yöntemler:}

Sakarya Üniversitesi Eğitim ve Araştırma Hastanesi Erişkin Alerji ve İmmunoloji Polikliniğine 20162018 yılları arasında ilaç alerjisi şikayeti ile başvuran hastaların dosyaları geriye dönük olarak incelendi. Araştırma tanımlayıcı tipte bir araştırmadır. Çalışma, Sakarya Üniversitesi Tıp Fakültesi Girişimsel Olamayan Etik Kurul tarafından onaylandı. 
sinde klinik ve laboratuvar bulgularının alerjik tablo ile uyumlu olması, var olan tabloyu açıklayacak diğer etiyolojik faktörlerin dışlanmasına dikkat edilerek ilaç alerji tanısı doğrulanan hastalar değerlendirmeye alındı. Çalışmaya 18 yaş üstü ve belirtilen tarihler arasında polikliniğe başvuranlardan sadece Tip 1 reaksiyon şeklinde ilaç alerjisi olan 108 hasta dahil edildi. Tip 1 aracilı olmayan, cox-1 aracılı nonsteroid antienflamatuar (NSAii) ilaç alerjisi olan 105 hasta çalışmaya dahil edilmedi.

Hastaların dosyalarından yaş, cinsiyet, anamnez, reaksiyona neden olan şüpheli ilaç(lar), deri test ve oral provokasyon test sonuçları, plasebo ile semptom oranları, tanısı doğrulanan ve alternatif olarak güvenle kullanabildikleri ilaç(lar) ile ilgili veriler toplandı. Tanımlayıcı istatistikler; sayı, yüzde ve ortalama \pm standart sapma olarak ifade edilmiştir. $p$ değerinin istatistiksel anlamlılık düzeyi 0,05 'in altı olarak kabul edilmiştir. Çalışmanın güç analizi post-hoc olarak yapılmıştır. Anaflaksi öyküsü, çoklu ilaç anamnezi, tüm ilaç anamnezi ve hangi ilaca karşı reaksiyon geliştiğini bilip bilmeme durumlarının plasebo sonuçları ile aralarındaki ilişkiyi incelemek için Fisher kesin ki-kare testi kullanıldı.

\section{Deri test ve oral provokasyon test uygulama protokolü;}

Hasta dosyalarında yer alan deri testleri ENDA kılavuzu doğrultusunda yapıldı. Pozitif kontrol olarak histamin (10 mg/mL), negatif kontrol olarak ise \%0,09'luk steril salin kullanılmıştır. Hasta anamnezine dayanarak şüphenilen ilaç ile veya alternatif bir ilaç kullanarak yapılan deri prick testinin negatif sonuç vermesi durumunda iDT yapılmıştır. 20 dakika sonra test bölgesinde bakılan ödem çapının, negatif kontrole göre 3 mm'nin üzerinde saptanması halinde test pozitif kabul edilmiştir. Deri testi pozitif saptanan hastalara o ilaca alerjisi var kabul edilerek OPT uygulanmadı.

Deri testleri negatif olduğu durumda ve hayatı tehdit edici anafilaksi öyküsü yok ise OPT ile teste devam edildi. Anksiyetesi olan hastalara test öncesi plasebo verilerek başlandı. Tüm OPT hastane şartlarında ve acil müdahale imkanları sağlandıktan sonra gerçekleştirildi. OPT öncesi hastanın vital bulguları ve pefmetre değerleri kaydedildi. Öncesinde anafilaksi öyküsü olan hastalara damar yolu açıldı. Oral uygulamada önce ilacın 1/4'ü verildi. 40 dakika sonra herhangi bir semptom yok ise geri kalan 3/4'ü verildi. İntravenöz veya subkutan provokasyonlarda önce ilacın 1/10 ‘ verilerek teste başlandı, sonrasında artan dozlarda alması gerekli doza ulaşıldı. Semptom ve PEF değerlerinde değişkenlik olmaması durumunda test negatif kabul edildi ve ilacı güvenle alabileceği doğrulandı. ${ }^{6,11,12}$

ilaç grupları aşağıdaki şekilde ayrıldı;

- Antibiyotikler: Penisilin, Sefalosporin, Makrolid, Kinolon, Metranidazol, diğerleri (Linkozamidler, Aminoglikozitler)

- Analjezikler: Parasetamol, cox2 inhibitörleri ve diğer grup analjezikler

- GIS etkili ilaçlar: Proton pompa inhibitörleri, H2 blokerler, Metpamid

- Vitaminler: B12, Fe, D vit

- Diğer ilaçlar: Metilprednizolon, inhaler ilaçlar, Feniramin Maleat ,Monural, Betaserc Metformin, Bisakodil, Essitalopram, Hiyasin n Butilbromür vs..

\section{Bulgular:}

Verileri çalışmaya dahil edilen 108 hastanın kadın/erkek oranı $96(\% 88,9) / 12(\% 11,1)$, yaş ortalaması 44,1 $\pm 12,1$ SS idi.
Sakarya Tip Dergisi

2018;8(4):759-765

IERziočLU ve Ank.

Sakarya Bölgesi Ekken Tip

ilaç Alerijisi Test Sonuçlan 
Hastaların anamnezleri değerlendirildiğinde 27 (\%25) hastada anafilaksi kliniği, $63(\% 58,3)$ hastada aynı anda birden çok ilaç alımı ile alerji gelişme öyküsü, $45(\% 41,7)$ hastada tek ilaç alımı ile alerji gelişme öyküsü mevcuttu. Hastaların 21'i $(\% 19,4)$ hangi ilaca alerjisinin olduğunu bilmediğini, 8’i $(\% 7,4)$ tüm ilaçlara alerjisi olduğunu, 77 'si $(\% 71,3)$ birden fazla kere ilaç alerjisi yaşadığını bildirdi.

Hastaların anamnezleri şüpheli ilaçlar üzerinden değerlendirildiğinde; hastaların 60'ında ( \%55) bir veya birden fazla antibiyotik ile alerji öyküsü mevcuttu. Şüpheli antibiyotik öyküsü verenlerin 47'sinde (\%78) penisilin veya sefalosporin grubundan en az birine karşı alerji şüphesi mevcuttu. Antibiyotik alerjisi olduğundan şüphelenilen 60 kişi; \%55'i penisilin grubuna, \%46,7'si sefalosporin grubuna, \%20,0'si kinolon grubuna, \%13,3'ü makrolid grubuna, \%5,0'i metranidazol grubuna ve \%1,7’si diğer grup antibiyotiklere karşı alerji şüphesi şeklinde dağılmaktaydı.

Hastaların 41'inde (38\%) analjezik kullanımına bağlı alerji öyküsü mevcuttu. Bunların \% 34,1'inde parasetamole karşı alerji şüphesi öne çıkıyordu. 108 hastanın 81'inde (\%75) ise en az bir antibiyotik ve bir analjezik ile alerji öyküsü mevcuttu (Şekil 1).

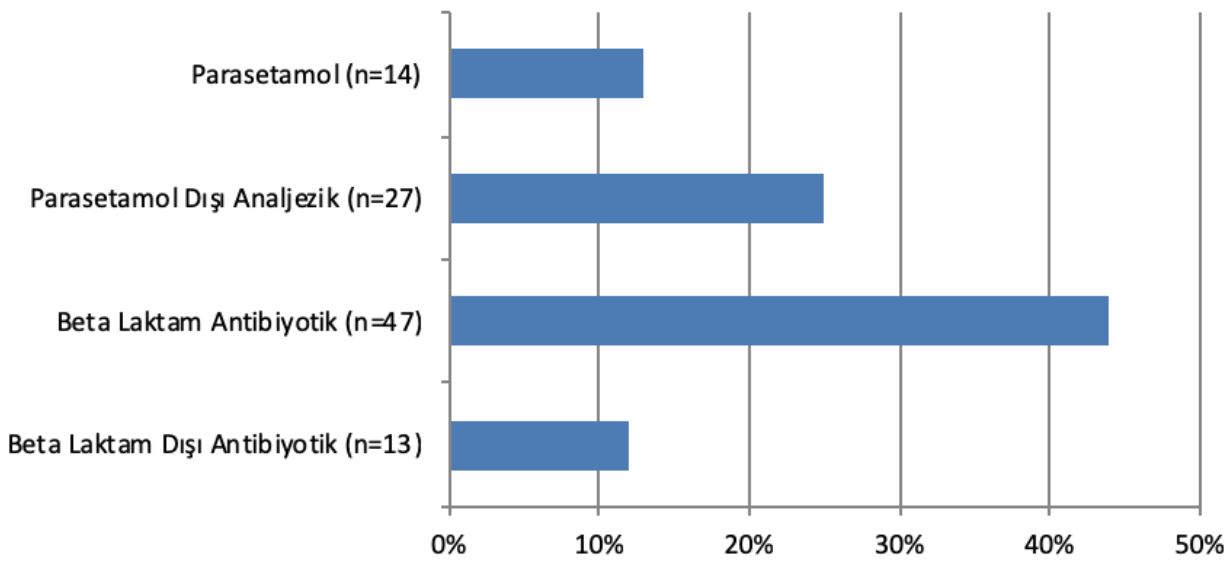

Şekil 1. Alerji öykülerinin bazı ilaç türlerine göre dağlımı (" $n$ " ifadesi ilaç alerji şüpheli kişi sayısını, “\%” ifadesi ilaç alerji şüpheli kişilerin 108 hasta içindeki oranını belirtmektedir. [Bazı kişilerde 1'den fazla ilaca karşı alerji öyküsü mevcuttu.])

Diğer şüpheli ilaçların dağılımı ise; $7(\% 6,5)$ hastada gastrointestinal sisteme etkili ilaçlar, 6 hastada $(\% 5,6)$ vitamin preparatları, 15 (\% 13,9) hastada ise diğer gruplardan ilaçlar şeklindeydi.

illaç alerjisi ile başvuran hastalara alerji tanısının doğrulanması için şüpheli ilaçlarla alerji testleri yapıldı. 38 hastaya 53 şüpheli ilaç ile yapılan testlerin sonucunda, 14 ilaç ile deri testi pozitifliği, 4 ilaç ile opt pozitifliği saptanarak toplamda 17 kişide 18 ilaç alerjisi saptandı. Tanısı doğrulanan ilaçların dağıımı; 7 antibiyotik (4 B-laktan grubu, 3 makrolid grubu), 6 analjezik ( 3 parasetamol grubu, 3 metamizol grubu), 1 metil prednisolon, 2 feniramin maleat, 2 ranitidin olarak bulundu. Opt pozitfliği ile tanısı doğrulanan ilaçların dağılımı ise; 1 klaritromisin, 1 parasetamol, 2 feniramin maleat idi. İlaç alerjisi ile başvuran hastaların güvenle kullanabilecekleri alternatif ilaçları saptamak amacı ile 80 hastaya toplamda 105 alternatif ilaç ile test yapıldı. Bunun 71 'i antibiyotik ( 41 klaritromisin,13 B-laktam grubu, 17 kinolon), 26'sı analjezik ( 10 parasetamol, 2 asetilsalisilik asit, 1 NSAiD, 13 cox2 gurubu), 8'i diğer gruptan ilaçlardan oluşuyordu. 80 hastanın 49'una $(\% 61,3)$ deri testleri ve 
OPT, 31 'ine $(\% 38,7)$ sadece OPT yapıldı. 105 alternatif ilacın kullanıldığı testlerin sonucunda hastaların \%11,4'ünde pozitiflik saptandı. 8 hastada deri testinin 4 hastada OPT 'nin pozitif bulunduğu ilaçların 11'i antibiyotik ( kinolon 1, klaritromisin 5, penisilin 1, sefalosporin 4) ve 1'i parasetamol idi.

Plasebo sadece 35 hastaya uygulandı, $12(\% 34,3)$ hastada plasebo ile reaksiyon gözlendi. Yapılan Fisher kesin ki-kare testinde plaseboda reaksiyon gözlenen kişiler ile anafilaksi ve anamnezde verilen öyküler arasında anlamlı ilişki saptanmadı (Bkz. Tablo 1).

\begin{tabular}{|c|c|c|c|c|}
\hline & Plasebo Yanitı(+) & Plasebo yanitı (-) & $P$ değeri* & Power $(\%)$ \\
\hline Anaflaksi Öyküsü(+) & $4(57,1 \%)$ & $3(42,9 \%)$ & \multirow{2}{*}{0,200} & \multirow{2}{*}{28,93} \\
\hline Anaflaksi Öyküsü(-) & $8(28,6 \%)$ & $20(71,4 \%)$ & & \\
\hline Çoklu ilaç Anamnezi(+) & $9(36,0 \%)$ & $16(64,0 \%)$ & \multirow{2}{*}{1,000} & \multirow{2}{*}{4,78} \\
\hline Çoklu ilaç Anamnezi(-) & $3(30,0 \%)$ & $7(70,0 \%)$ & & \\
\hline Tüm İlaç Anamnezi(+) & $3(60,0 \%)$ & $2(40,0 \%)$ & \multirow{2}{*}{0,313} & \multirow{2}{*}{25,21} \\
\hline Tüm İlaç Anamnezi(-) & $9(30,0 \%)$ & $21(70,0 \%)$ & & \\
\hline İlacı Biliyor** & $9(39,1 \%)$ & $14(60,9 \%)$ & \multirow{2}{*}{0,476} & \multirow{2}{*}{12,74} \\
\hline İlacı Bilmiyor** & $3(25,0 \%)$ & $9(75,0 \%)$ & & \\
\hline
\end{tabular}

\section{Tartışma:}

Çalışmada Sakarya Üniversitesi Tıp Fakültesi Eğitim Araştırma Hastanesi, alerji ve immunoloji polikliniğine 2016-2018 yılları arasında erken tip ilaç alerjisi nedeni ile başvuran 108 hasta değerlendirildi.

Hastanın verileri incelendiğinde kadın/erkek oranı $96(\% 88,9) / 12(\% 11,1)$, yaş ortalaması 44,1 12,1 SS idi. Çalışmada öyküye dayalı B-laktam antibiyotik alerji oranları penisilin $\% 55$, sefalosporin $\% 46,7$, analjezikler $\% 38$ şeklindeydi. Alternatif amaçla yapılan testlerde $\% 11,4$ oranında pozitiflik saptandı. Plasebo uygulanan 35 hastanın \%34,3'ünde plasebo ile reaksiyon gözlendi.

İlaç alerjisinin kadınlarda erkeklere oranla daha fazla görüldüğünü destekleyen birçok yayın mevcuttur ve genelde 2:1 oranında bildirilmektedir. $1^{3}$ Dona I. ve arkadaşları yaptıkları çalışmada 6 yıl içinde ilaç alerjisi ile başvuran 4460 hastayı incelemiş ve kadın /erkek oranı $2880(\% 64,58)$ / $1580(\% 35,42)$ ile 2:1 oranında, yaş ortalamasını ise $43.71(15,82)$ saptamışlardır. ${ }^{14}$ Bu çalışmada da ise kadın/erkek oranı $96(\% 88,9) / 12(\% 11,1)$ ile büyük bir oranın kadınlardan oluştuğu bulundu. Yaş ortalaması ise $44,1 \pm(12,1)$ benzer şekilde bulundu. Kadın cinsiyet ilaç alerjisi için artmış risk faktörü olmasına rağmen bu çalışmada 9:1 gibi çok yüksek oranda bulunması dikkat çekici bir noktadır.

İlaç aşırı duyarılığına en sık neden olan ilaçlar antibiyotikler ve NSAiil'lardır. Türkiye'den yapılan bir çalışmada öyküye dayalı B-laktam antibiyotik alerji oranı \%51,2 ve NSAii oranı $\% 41,5$ bulunmuştur. ${ }^{15} \mathrm{Bu}$ çalışmada da bu oranlar penisilin \%55, sefalosporin \%46,7, analjezikler $\% 38$ ile benzer şekilde bulunmuştur. Tanısal testler sonucunda ise hastaların \%6,5 'inde antibiyotik alerjisi,
Sakarya Tıp Dergisi

$2018 ; 8(4): 759-765$

TERZioĞLU ve Ark. TERzioGu ve Ark. Sakarya Bölgesi Erken Tip ilaç Alerijsi Test Sonuçlan 
Sakarya Tup Dergisi

2018;8(4):759-765

TERzioĞLU ve Ark.

Sakarya Bölgesi Erken Tip ilaç Alerjisi Test Sonuçları
$\% 2,8^{\prime}$ inde ise analjezik alerjisi saptand.

Çalışmada 38 hastaya 53 şüpheli ilaç ile, 80 hastaya 105 alternatif ilaç ile test yapıldı. Şüpheli ilaç ile yapılan testlerde $17(\% 44,7)$ hastada pozitiflik saptandı. Alternatif amaçla yapılan testlerde \%11,4 oranında pozitiflik saptandı. Türkiye'de üç merkezin katıldığı, Çelik GE ve arkadaşlarının yaptığı çalışmada alternatif ilaç testlerinde bu çalışma ile benzer şekilde \%11,7 oranında pozitiflik saptamışlardır. ${ }^{16}$ Fakat tanısal amaçlı yapılan testlerde \%27 pozitiflik ile bu çalışmadan daha düşük oranda ilaç tanısı doğrulanmıştır. Bu sonuçlar doğrultusunda ilaç alerjisinde öyküye dayalı ilaçların direkt yasaklanmasının doğru olmadığı ve alternatif ilaç seçiminde muhakkak öncesinde testlerin yapılması gerektiği sonucuna varılabilir.

Plasebo, anksiyetesi olduğu düşünülen 35 hastaya test öncesinde uygulandı, Plasebo uygulanan hastaların \% 34,3'ünde plasebo ile reaksiyon gözlendi. Hastaların ilaç alerjisini bir kere bile deneyimlemeleri hastalarda psikolojik kalııı etkileri olduğunu göstermektedir. Hastaların verdikleri öykü ile karşılaşııııldığında anaflaksi, çoklu ilaç anamnezi ve tüm ilaç anamnezi pozitif kişilerde negatif kişilere oranla daha yüksek oranda plaseboya yanıt pozitifliği saptandı. Fakat bu ilişki istatistiksel olarak anlamlı değildi. Araştırma kayıtlardan yapıldığı için güç analizi post-hoc olarak yapıımıştır. Post-hoc güç analizinin düşük çıkması nedeniyle aynı karşılaştırmanın ileriki çalışmalarda daha yüksek sayıda hasta büyüklüğüyle ve mümkünse tüm hastalara plasebo uygulanmış olarak yapılması daha uygundur.

İlaç alerjisinde ayrıntılı alınan anamnez doğrultusunda şüpheli ilacın saptanması ve gerekli tanısal testlerin uygulanması esastır. ${ }^{17}$ Çalışmada ilaç alerjisi nedeni ile başvuran hastaların \%58 'i aynı anda birden fazla ilaç alımı ile, \%19,4 'ü hangi ilaca alerjisi olduğunu bilmeyerek, \%7,4'ü tüm ilaçlara alerjisi olduğunu bildirerek başvurdu. Tüm bu belirsizlikler ilaç alerjisini değerlendirmede zorluklar yaratmakta ve ilaç alerji tanı konma oranlarını düşürmektedir. Hastaların \%71,3 ‘ü birden fazla kere ilaç alerjisi yaşadığı halde daha öncesinde tanısal amaçlı doktor başvurularının olmaması hasta ve hekimlerin bu konuda doğru yaklaşımda bulunamadıklarını göstermektedir.

Sonuç olarak hastaların ilaç alerjisi yaşadığında öykünün doğru alınması, ilaç isimlerinin kaydedilmesi, alerji uzmanlarına yönlendirilerek tanısal ve alternatif ilaç testlerinin yapılması hastaların mükerrer yaşadıkları ilaç alerjilerinin önüne geçilip ilaç kullanımı konusunda anksiyeteleri azaltılabilir. Bununla birlikte gereksiz ilaç kısıtlamalarını önüne geçilebilir. 
1. Johansson SG, Bieber T, Dahl R, Friedmann PS, Lanier BQ, Lockey $\mathrm{RF}$, et al. Revised nomenclature for allergy for global use: Reprt of the Nomenclature Review Committee of the World Allergy Organization. J Allergy Clin Immunol 2004;113:832-6

2. Pichler WJ, Adam J, Daubner B, Gentinetta T, Keller M, Yerly D, Drug hypersensitivity reactions: Pathomechanism and clinical symptoms. Med Clin N Am 2010;94:645-64

3. Celik GE, Pichler WJ, Adkinson NF. Drug allergy. Middleton's Allergy Principles and Practice 8th ed. Philadelphia: Elsevier Saunders; 2014:1274-95

4. Demoly P, Bousquet J. Epidemiology of drug allergy.Curr Opin Allergy Clin Immunol 2001;1:305-10

5. Gomes ER, Demoly P. Epidemiology of hypersensitivity drug reactions. Curr Opin Allergy Clin Immunol 2005

6. ÇelikGE. Illaç Aşıı Duyarlılık Reaksiyonlarına Yaklaşım Ulusal Rehber. 1. Baskı. Ankara: Bilimsel Tıp Yayınevi, 2014; 1-6

7. Lazarou J, Pomeranz BH, Corey PN. Incidence of adverse drug reac tions in hospitalized patiens: a meta-analysis of prospective studies. JAMA 1998;15;2791200-5

8. Demoly P, Adkinson NF, Brockow K, Castells M, Chiriac AM, Greenberger PA, et al. International Consensus on drug allergy. Allergy 2014;69(4):420-37.

9. Gelincik A, Özşeker ZF, Çolakoğlu B, Dal M, Büyüköztürk S. Antibiyotiklere bağlı hipersensitivite reaksiyonları: Alternatif antibiyotik saptanmasında provakasyon testlerinin önemi. Asthma Allergy Immunol 2013;11(1):23-31.
10. Kowalski ML, Asero R, Bavbek S, Blanca M, Blanca-Lopez N, Bochenek $\mathrm{G}$, et al. Classification and practical approach to the diagnosis and management of hypersensitivity to nonsteroidal anti-inflammatory drugs. Allergy 2013;68:1219-32.

11. Aberer W, Kranke B. Provocation tests in drug hypersensitivity. Immunol Allergy Clin North Am 2009;29(3):567-84.

12.lammatteo M, Alvarez Arango S, Ferastraoaru D, Akbar N, Lee AY, et al. Safety and Outcomes of Oral Graded Challenges to Amoxicillin without Prior Skin Testing. J Allergy Clin Immunol Pract. 2018;18:2213-2198

13.Adkinson NF Jr. Risk factors for drug allergy. J Allergy Clin Immunol 1984;74(4):567-72.

14.Doña I, Blanca-López N, Torres MJ, García-Campos J, García-Núñez I, Gómez F, et al. Drug hypersensitivitiy reactions: Response patterns, drug involved and temporal variations in a large series of patients. J Investig Allergol Clin Immunol 2012;22(5):363-71.

15. Kurt E, Demir AU, Cadirci O. Immediate type drug hypersensitivity reactions and associated risk factors in an adult Turkısh men population. Iran J Allergy Asthma Immunol 2010;9:245-50

16. Çelik GE, Karakaya G, Öztürk AB, Gelincik A, Abadoğlu O, Sin A, Et al. Drug allergy in tertiary care in Turkey: Results of a national survey. The ADAPT study:Adult drug allergy perception in Turkey. Allergol Immunopathol. 2013:23;34-36

17. Schnyder B. Approach to the patient with drug allergy. Med Clin North Am 2010;94(4):665-79
Sakarya Tıp Dergisi

2018;8(4):759-765

TERZioĞLU ve Ark.

Sekarioçu ve Ark.

Sakarya Bölgesi Erken Tip
ilaç Alerjisi Test Sonuçları 